\title{
Population-Based Estimate of Melioidosis, Kenya
}

\author{
Esther M. Muthumbi, Nicola C. Gordon, \\ George Mochamah, Sammy Nyongesa, \\ Emily Odipo, Salim Mwarumba, Neema Mturi, \\ Anthony O. Etyang, David A.B. Dance, \\ J. Anthony G. Scott, Susan C. Morpeth
}

Melioidosis is thought to be endemic, although underdiagnosed, in Africa. We identified 5 autochthonous cases of Burkholderia pseudomallei infection in a case series in Kenya. Incidence of B. pseudomallei bacteremia in Kenya's Kilifi County is low, at 1.5 cases per million person-years, but this result might be an underestimate.

$B$ urkholderia pseudomallei, the causative agent of melioidosis, is a gram-negative bacillus endemic particularly in northern Australia and South and Southeast Asia. Worldwide, $B$. pseudomallei causes $\approx 165,000$ cases of disease and $\approx 89,000$ deaths annually $(1)$. The presence of B. pseudomallei in Africa has been demonstrated by sporadic cases of melioidosis reported in travelers returning from countries including Kenya (2). Indigenous cultureconfirmed cases have been reported in only 4 countries in Africa, mainly from research centers with diagnostic laboratory facilities (3).

The first case of melioidosis linked to Kenya was diagnosed in 1982 in a tourist from Denmark who had visited Nyali (an area of Mombasa City), $\approx 50 \mathrm{~km}$ south of the town of Kilifi (2). Follow-up clinical surveillance in Nairobi and environmental surveillance from other regions in Kenya yielded no B. pseudomallei isolates (4). However, growing concerns over possible underestimation of the disease in potentially endemic areas, including in tropical Africa, have led to calls for improved surveillance (5).

In 2010, at Kilifi County Hospital ( $\mathrm{KCH})$, we isolated B. pseudomallei from the blood culture of a 3-year-old child after a near-drowning accident in a seasonal river.

Author affiliations: KEMRI-Wellcome Trust Research Programme, Kilifi, Kenya (E.M. Muthumbi, N.C. Gordon, G. Mochamah,

S. Nyongesa, E. Odipo, S. Mwarumba, N. Mturi, A.O. Etyang, J.A.G. Scott, S.C. Morpeth); London School of Hygiene \& Tropical Medicine, London, UK (N.C. Gordon, D.A.B. Dance, J.A.G. Scott, S.C. Morpeth); Lao-Oxford-Mahosot Hospital-Wellcome Trust Research Unit, Vientiane, Laos (D.A.B. Dance); University of Oxford, Oxford, UK (D.A.B. Dance, J.A.G. Scott, S.C. Morpeth)

DOI: https://doi.org/10.3201/eid2505.180545
The identity of the isolate was confirmed by real-time PCR targeting the type III secretion system genes of B. pseudomallei ( 6 ), and the isolate was later sequenced for a study of geographic dissemination of B. pseudomallei (7). After this identification, we conducted a retrospective analysis of archived blood culture isolates collected during 1994-2012 to investigate possible missed cases of invasive B. pseudomallei infection.

\section{The Study}

During 1994-1998, blood culture was performed on all febrile patients admitted to the pediatric wards at $\mathrm{KCH}$. Since 1998, all pediatric patients $<15$ years of age admitted, except those having trauma, burns, or elective surgery, have had blood samples drawn for culture. Surveillance for patients $\geq 15$ years of age began in 2007 ; blood samples are drawn at admission for cultures on patients meeting clinical criteria for possible invasive bacterial disease. Since 2002, hospitalization events have been linked to the Kilifi Health and Demographic Surveillance System (KHDSS), which monitors the population of $\approx 280,000$ over an area of $891 \mathrm{~km}^{2}(8)$. Informed consent is obtained from all patients participating in the surveillance, including for storage of isolates and future use of clinical data.

Blood samples for bacterial cultures were collected in BACTEC Peds Plus or BACTEC Plus Aerobic/F bottles (Becton Dickinson, https://www.bd.com) and incubated on a BACTEC FX 9050 Automated Blood Culture instrument (Becton Dickinson). Nonfastidious, oxidase-positive, gram-negative bacilli were identified by using API 20NE test kits (bioMérieux, https://www.biomerieux.com). We reviewed all gentamicin-resistant, glucose-nonfermenting, gram-negative rods, with the exception of Pseudomonas aeruginosa, even if the API 20NE identification was acceptable, to account for difficulties in speciating Burkholderia spp. with biochemical methods.

A total of 86,582 patients $<15$ years of age were admitted during 1994-2012 and 18,864 patients $\geq 15$ years of age during 2007-2012. Surveillance identified 33 gentamicin-resistant, glucose-nonfermenting bacilli in 14,235 positive blood cultures from patients $<15$ years of age and 5 gentamicin-resistant, glucose-nonfermenting bacilli in 705 positive blood cultures from patients $\geq 15$ years of age (Figure). We retrieved all 38 isolates from storage for PCR, which we performed using published primer and probe sequences $(6)$. 


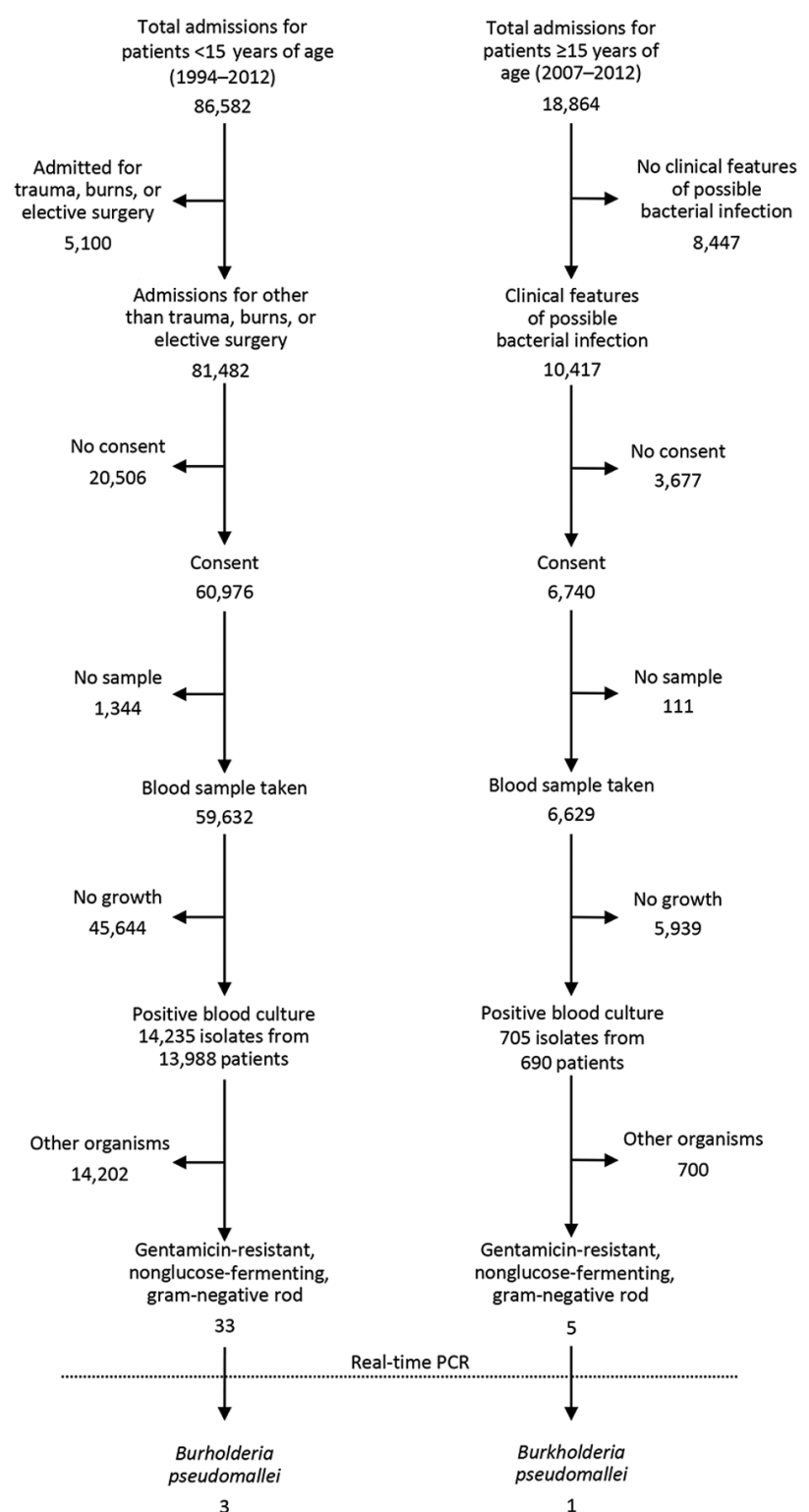

Figure. Identification of gentamicin-resistant, glucose-nonfermenting bacilli and Burkholderia pseudomallei from isolates collected from patients at Kilifi County Hospital, Kilifi, Kenya, 1994-2012.

We identified 4 isolates as $B$. pseudomallei by PCR, including the index isolate from 2010 (Table 1; Appendix, https://wwwnc.cdc.gov/EID/25/5/18-0545-App1.pdf). One isolate was previously identified as $B$. cepacia, and 2 were previously labeled as Pseudomonas species. We identified a fifth B. pseudomallei case in July 2014 in a 68-year-old female patient with diabetes mellitus and bilateral cervical abscesses (Table 1; Appendix). Blood culture results were negative, but aspirated pus grew $B$. pseudomallei, identified by API $20 \mathrm{NE}$ and confirmed by PCR.

None of the case-patients had any history of travel outside Kilifi County. Three died during the course of their admission. No further information is available for the 2 case-patients who survived because they were not residents of the area surveyed by KHDSS.

To estimate the incidence of melioidosis bloodstream infection, we divided the number of invasive B. pseudomallei cases among KHDSS residents by the sum of the annual midyear population counts during 2002-2012 for those $<15$ years of age and during 2007-2012 for those $\geq 15$ years of age. We also adjusted for the sensitivity of the surveillance to account for the proportion of patients not consenting to the surveillance study and those who did not have a blood culture drawn. For the period before 2002, we extrapolated age-specific population estimates by using a log-linear model of age-specific population data based on subsequent enumerations. The estimated incidence was 1.3 cases/ 1 million person-years of observation for those $<15$ years of age and 2 cases $/ 1$ million person-years of observation for those $\geq 15$ years of age (Table 2).

\section{Conclusions}

We identified 5 cases of melioidosis from a single surveillance site in Kenya. Despite reports suggesting that melioidosis is endemic but underdetected in the region (5), we demonstrated low incidence in this part of Kenya. Even so, B. pseudomallei has emerged as an underdiagnosed cause of sepsis in Kilifi County. The empirical treatment used for sepsis, ampicillin and gentamicin, does not cover B. pseudomallei. The lack of pathogenomonic clinical features makes it difficult to detect melioidosis clinically, especially in areas to which the disease is not endemic. In the series we report, 2 casepatients died before receiving definitive treatment, and only 1 case-patient received antimicrobial drugs recommended to treat melioidosis.

The integrated, population-based bacterial surveillance system in Kilifi County provides a unique opportunity to estimate incidence. Routine blood culture sampling of all admitted patients $<15$ years of age and eligible patients $\geq 15$ years of age eliminates reliance on clinical suspicion for bacteremic melioidosis. The use of molecular methods on isolates suspected to be $B$. pseudomallei will probably enhance case detection because $B$. pseudomallei is commonly misidentified or unidentified by culture (9). Only 2 isolates in our study were identified by using standard techniques, despite the reported good discriminatory performance of API 20NE in distinguishing B. pseudomallei and B. cepacia (10).

Our reported incidence rates might still be underestimated. Our data do not account for KHDSS residents who do not go to $\mathrm{KCH}$. For example, $\approx 64 \%$ of deaths in children $<5$ years of age in the KHDSS area occur at home or in other healthcare facilities (8). Furthermore, as 
Table 1. Clinical summary of patients with positive Burkholderia pseudomallei isolates, Kilifi, Kenya, 2002-2014*

\begin{tabular}{|c|c|c|c|c|c|c|c|c|c|c|c|c|}
\hline \multirow[b]{2}{*}{ Year } & \multirow[b]{2}{*}{ Age/sex } & \multirow[b]{2}{*}{ Clinical features } & \multirow{2}{*}{$\begin{array}{c}\text { Risk } \\
\text { factors }\end{array}$} & \multirow[b]{2}{*}{ Diagnosis $†$} & \multirow{2}{*}{$\begin{array}{l}\text { Culture } \\
\text { source }\end{array}$} & \multicolumn{5}{|c|}{ Antimicrobial sensitivity } & \multirow{2}{*}{$\begin{array}{l}\text { Days in } \\
\text { hospital }\end{array}$} & \multirow[b]{2}{*}{ Outcome } \\
\hline & & & & & & AMC & STX & TET & CAZ & IMI & & \\
\hline 2002 & $8 \mathrm{~d} / \mathrm{M}$ & $\begin{array}{l}\text { Fever, jaundice, } \\
\text { respiratory } \\
\text { distress }\end{array}$ & $\begin{array}{c}\text { None } \\
\text { identified }\end{array}$ & Neonatal sepsis & Blood & $S$ & $S$ & $S$ & $S$ & $\mathrm{~S}$ & 3 & Died \\
\hline 2008 & $7 \mathrm{~d} / \mathrm{M}$ & $\begin{array}{c}\text { Respiratory } \\
\text { distress }\end{array}$ & $\begin{array}{c}\text { None } \\
\text { identified }\end{array}$ & $\begin{array}{c}\text { Severe } \\
\text { pneumonia, } \\
\text { neonatal sepsis }\end{array}$ & Blood & $S$ & S & $S$ & S & $\mathrm{S}$ & 3 & Survived \\
\hline 2010 & $3 \mathrm{y} / \mathrm{F}$ & $\begin{array}{l}\text { Fever, } \\
\text { respiratory } \\
\text { distress }\end{array}$ & $\begin{array}{c}\text { Near- } \\
\text { drowning }\end{array}$ & $\begin{array}{c}\text { Severe } \\
\text { pneumonia, } \\
\text { septic shock }\end{array}$ & Blood & $S$ & S & S & $S$ & $\mathrm{~S}$ & 6 & Died \\
\hline 2011 & 52 y/M & $\begin{array}{c}\text { Persistent fever } \\
\text { and night } \\
\text { sweats of } \\
\text { unknown } \\
\text { duration }\end{array}$ & $\begin{array}{c}\text { None } \\
\text { identified }\end{array}$ & $\begin{array}{l}\text { Acute renal } \\
\text { failure, } \\
\text { meningitis }\end{array}$ & Blood & S & S & S & $S$ & $\mathrm{~S}$ & 5 & Died \\
\hline 2014 & $68 \mathrm{y} / \mathrm{F}$ & $\begin{array}{l}\text { Fever, bilateral } \\
\text { cervical neck } \\
\text { swellings }\end{array}$ & $\begin{array}{c}\text { Diabetes } \\
\text { mellitus }\end{array}$ & $\begin{array}{c}\text { Diabetes, } \\
\text { cervical } \\
\text { lymphadenitis }\end{array}$ & Pus swab & S & $S$ & $S$ & $S$ & $\mathrm{~S}$ & 40 & Survived \\
\hline
\end{tabular}

*AMC, amoxicillin/clavulanic acid; CAZ, ceftazidime; IMI, imipenem; S, susceptible; STX, sulfamethoxazole/trimethoprim; TET, tetracycline. †Diagnosis at time of admission.

demonstrated by the fifth case, the incidence of nonbacteremic infection might be higher because non-blood culture samples are not systematically collected. Only $50 \%-75 \%$ of patients with melioidosis are bacteremic (11), and culture has an estimated sensitivity of $60.2 \%$ for melioidosis (12). In addition, our screening method excluded gentamicin-susceptible isolates. If gentamicinsusceptible $B$. pseudomalle $i$ is as common in Kenya as reported in other areas (13), additional surveillance that includes these organisms could increase the reported incidence rates. Finally, melioidosis often is unevenly distributed within endemic areas, as noted in Thailand (14). Despite these factors, our results suggest that, although $B$. pseudomallei is present in tropical Africa, the incidence of invasive melioidosis is surprisingly low.

The differences in disease incidence in Africa and Asia are striking. Host factors, such as diabetes mellitus, might contribute, but environmental factors and agricultural practices, such as rice farming, are probably more important in permitting exposure to and environmental persistence and proliferation of the organism. Nonetheless, Kenya has been identified as environmentally suitable for B. pseudomallei because of its soil type, agricultural practices, and rainfall (1). Our study demonstrates the presence of $B$. pseudomallei in Kenya. Changes in climate and agricultural practices might lead to future increases in melioidosis, and ongoing surveillance is necessary.

\section{Acknowledgments}

We thank the nursing, clinical, and clerical staff of Kilifi County Hospital and the patients and their families.

The surveillance work was funded by the Wellcome Trust (core support to KEMRI-Wellcome Trust Research Program grant no. 203077) and by Gavi, the Vaccine Alliance, through support for a study of pneumococcal vaccine impact. J.A.G.S. is supported by a Wellcome Trust clinical research fellowship (no. 098532) and D.A.B.D. is funded by Wellcome grant no. 106698/Z/14/Z.

E.M.M. is supported through the DELTAS Africa Initiative [DEL-15-003]. The DELTAS Africa Initiative is an independent funding scheme of the African Academy of Sciences' (AAS) Alliance for Accelerating Excellence in Science in Africa and supported by the New Partnership for Africa's Development Planning and Coordinating Agency (NEPAD Agency) with funding from the Wellcome Trust, [107769/Z/10/Z] and the government of the United Kingdom. The views expressed in this publication are those of the authors and not necessarily those of AAS, NEPAD Agency, Wellcome Trust, or the UK government.

This paper is published with the approval of the director of the Kenya Medical Research Institute.

\section{About the Author}

Dr. Muthumbi is a medical epidemiologist at the KEMRIWellcome Trust Research Programme in Kenya. She is a doctoral student in infectious disease epidemiology.

\begin{tabular}{lcccccc}
\hline Table 2. Incidence of melioidosis in Kilifi County Hospital, Kilifi, Kenya, 1994-2012* & & \\
\hline Patient age group & No. cases & $\begin{array}{c}\text { No. case-patients } \\
\text { residing in KHDSS area }\end{array}$ & Study period & $\begin{array}{c}\text { Person-years } \\
\text { of observation }\end{array}$ & $\begin{array}{c}\text { Crude incidence } \\
(95 \% \mathrm{Cl})\end{array}$ & $\begin{array}{c}\text { Adjusted incidence } \\
(95 \% \mathrm{Cl})\end{array}$ \\
\hline$<15 \mathrm{y}$ & 3 & 2 & $1994-2012$ & $2,026,781$ & $1.0(0.12-3.56)$ & $1.3(0.17-5.17)$ \\
$\geq 15$ y & 1 & 1 & $2007-2012$ & 782,373 & $1.3(0.03-7.1)$ & $2.0(0.08-15.6)$ \\
\hline Overall & 4 & 3 & NA & $2,809,154$ & $1.1(0.22-3.12)$ & $1.5(0.35-5.0)$ \\
\hline
\end{tabular}

*KHDSS, Kilifi Health and Demographic Surveillance System; NA, not applicable.

†Incidence per $10^{6}$ person-years of observation, adjusted for nonconsenters and missing blood cultures among eligible consenters. 


\section{References}

1. Limmathurotsakul D, Golding N, Dance DAB, Messina JP, Pigott DM, Moyes CL, et al. Predicted global distribution of Burkholderia pseudomallei and burden of melioidosis. Nat Microbiol. 2016;1:15008 http://dx.doi.org/10.1038/nmicrobiol.2015.8

2. Bremmelgaard A, Bygbjerg I, Høiby N. Microbiological and immunological studies in a case of human melioidosis diagnosed in Denmark. Scand J Infect Dis. 1982;14:271-5. http://dx.doi.org/ 10.3109/inf.1982.14.issue-4.05

3. Birnie E, Wiersinga WJ, Limmathurotsakul D, Grobusch MP. Melioidosis in Africa: should we be looking more closely? Future Microbiol. 2015;10:273-81. http://dx.doi.org/10.2217/fmb.14.113

4. Batchelor BI, Paul J, Trakulsomboon S, Mgongo M, Dance DAB. Melioidosis survey in Kenya. Trans R Soc Trop Med Hyg. 1994;88:181. http://dx.doi.org/10.1016/0035-9203(94)90286-0

5. Currie BJ, Dance DAB, Cheng AC. The global distribution of Burkholderia pseudomallei and melioidosis: an update. Trans R Soc Trop Med Hyg. 2008;102(Suppl 1):S1-4. http://dx.doi.org/ 10.1016/s0035-9203(08)70002-6

6. Novak RT, Glass MB, Gee JE, Gal D, Mayo MJ, Currie BJ, et al. Development and evaluation of a real-time PCR assay targeting the type III secretion system of Burkholderia pseudomallei. J Clin Microbiol. 2006;44:85-90. http://dx.doi.org/10.1128/ jcm.44.1.85-90.2006

7. Chewapreecha C, Holden MT, Vehkala M, Valimaki N, Yang Z, Harris SR, et al. Global and regional dissemination and evolution of Burkholderia pseudomallei. Nat Microbiol. 2017;2:16263. http://dx.doi.org/10.1038/nmicrobiol.2016.263

8. Scott JAG, Bauni E, Moisi JC, Ojal J, Gatakaa H, Nyundo C, et al. Profile: the Kilifi Health and Demographic Surveillance System (KHDSS). Int J Epidemiol. 2012;41(3):650-7. http://dx.doi.org/ 10.1093/ije/dys062
9. Amornchai P, Chierakul W, Wuthiekanun V, Mahakhunkijcharoen Y, Phetsouvanh R, Currie BJ, et al. Accuracy of Burkholderia pseudomallei identification using the API 20NE system and a latex agglutination test. J Clin Microbiol. 2007;45:3774-6. http://dx.doi.org/10.1128/jcm.00935-07

10. Kiratisin P, Santanirand P, Chantratita N, Kaewdaeng S Accuracy of commercial systems for identification of Burkholderia pseudomallei versus Burkholderia cepacia. Diagn Microbiol Infect Dis. 2007;59:277-81. http://dx.doi.org/10.1016/ j.diagmicrobio.2007.06.013

11. Wiersinga WJ, Virk HS, Torres AG, Currie BJ, Peacock SJ, Dance DAB, et al. Melioidosis. Nat Rev Dis Primers. 2018; 4:17107. http://dx.doi.org/10.1038/nrdp.2017.107

12. Limmathurotsakul D, Jamsen K, Arayawichanont A, Simpson JA, White LJ, Lee SJ, et al. Defining the true sensitivity of culture for the diagnosis of melioidosis using Bayesian latent class models. PLoS ONE. 2010;5:e12485. http://dx.doi.org/10.1371/ journal.pone.0012485.

13. Podin Y, Sarovich DS, Price EP, Kaestli M, Mayo M, Hii K, et al. Burkholderia pseudomallei isolates from Sarawak, Malaysian Borneo, are predominantly susceptible to aminoglycosides and macrolides. Antimicrob Agents Chemother. 2014;58(1):162-6. https://dx.doi.org/10.1128/aac.01842-13

14. Vuddhakul V, Tharavichitkul P, Na-Ngam N, Jitsurong S, Kunthawa B, Noimay P, et al. Epidemiology of Burkholderia pseudomallei in Thailand. Am J Trop Med Hyg. 1999;60:458-61. http://dx.doi.org/10.4269/ajtmh.1999.60.458

Address for correspondence: Esther M. Muthumbi, KEMRI-Wellcome Trust Research Programme, PO Box 230, Kilifi, Kenya; email: emuthumbi@kemri-wellcome.org

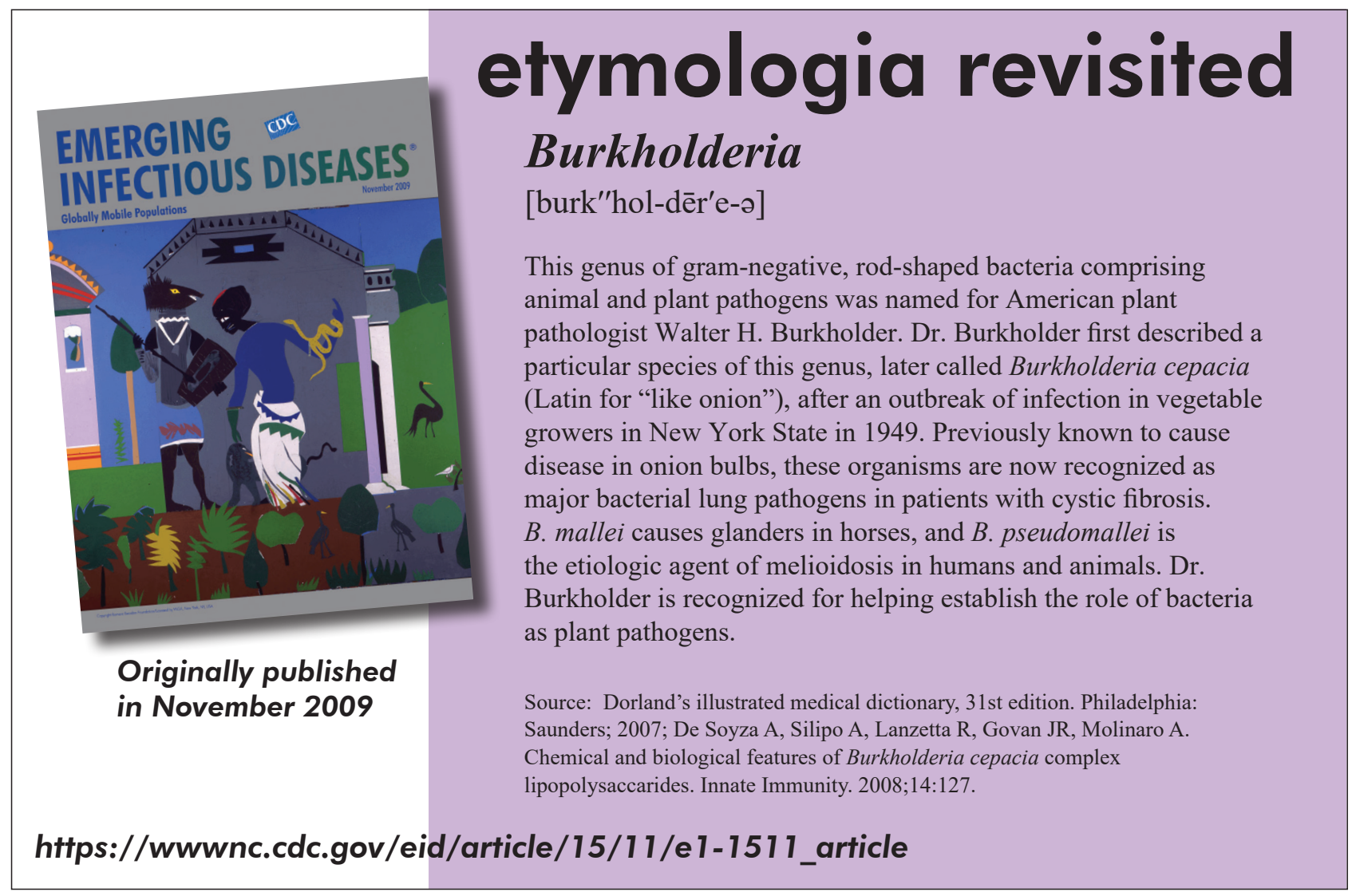

